\title{
ESTRUTURA DE CAPITAIS COMPARADA: BRASIL E MERCADOS EMERGENTES
}

COMPARATIVE CAPITAL STRUCTURE: BRAZIL AND EMERGING MARKETS

\section{RESUMO}

Este artigo analisa comparativamente o padrão da estrutura de capitais de empresas em mercados emergentes por meio de uma discussão analítica da literatura que emprega amostras de empresas de vários países e as analisam conjuntamente de forma seccional. A influência de fatores explicativos em relação ao país é comparada ao poder explicativo do setor de atividades e de fatores da firma. O artigo oferece diversos fatos estilizados identificados a partir dessa revisão da literatura. De forma geral, os fatores da firma parecem dominar os fatores do país, que, nem por isso, deixam de ter importância. Já os fatores do setor de atividade são pouco importantes. O endividamento dos mercados emergentes aumentou ao longo dos anos e a proteção ao credor e ao investidor tem um impacto favorável sobre ele. As hipóteses de M\&M são apenas parcialmente sustentadas pela evidência empírica em mercados emergentes.

\section{Ricardo Pereira Câmara Leal \\ Professor do Instituto Coppead de Administração, Universidade Federal do Rio de Janeiro \\ ricardoleal@coppead.ufrj.br}

Recebido em 27.03.2008. Aprovado em 11.08.2008

Avaliado pelo sistema double blind review

Editor Científico: Organizadores do Fórum

\begin{abstract}
This article offers a comparative analysis of capital structure patterns of firms in emerging markets by means of an analytical survey of the literature that employs cross section samples of firms from many countries and analyses them jointly. This article does not focus on the analysis of capital structure on a country by country basis. Only listed firms are discussed. The influence of country level explanatory factors is compared to the explanatory power of industry level and firm level factors. The main deliverables are several stylized facts identified in the survey of the literature. Country level factors are not irrelevant even though firm level factors seem to dominate them. Yet, industry level factors are not very important. Debt ratios of emerging market firms have risen over time and the degree of creditor and investor protection have a favorable impact over them. The MEM hypotheses are only partially supported by the emerging market evidence.
\end{abstract}

PALAVRAS-CHAVE Estrutura de capitais, financiamento de empresas, Brasil, mercados emergentes, mercado de capitais KEYWORDS Capital structure, corporate financing, Brazil, emerging markets, capital markets. 


\section{INTRODUÇÃo}

Este artigo visa produzir fatos estilizados sobre a estrutura de capitais em mercados emergentes por meio da revisão da literatura empírica que emprega amostras seccionais ou temporais que incluam empresas de vários mercados emergentes. O foco do artigo é o exame de determinantes da estrutura de capital de forma conjunta para vários países emergentes, privilegiando artigos com amostras de várias regiões e não estudos isolados. Há vários estudos que procuraram analisar a evolução da estrutura de capitais de empresas em mercados emergentes tanto no tempo quanto de forma seccional. A apresentação desses estudos e de suas principais conclusões ou fatos estilizados é feita em duas partes.

Em primeiro lugar, são discutidos os estudos mais antigos, que consideram a década de 1980 , predominando estudos descritivos. A seguir, os estudos de períodos mais recentes são apresentados com modelos seccionais e com análises das empresas no tempo. A análise da influência do país de origem e do setor de atividade, além dos fatores referentes à firma, é central para os estudos desse grupo, que procuram fatores explicativos para as diferenças entre os padrões de financiamento das empresas nos diversos países considerados. Os fatores relativos ao país são indicadores tais como índices de cumprimento das leis, de risco político, taxas de inflação e outras variáveis macroeconômicas, além de variáveis mudas denotando o país de origem. Finalmente, os fatores do setor de atividade em geral resumem-se a variáveis categóricas que classificam as firmas segundo seus setores de atividade. Em cada uma das seções, é oferecida uma breve discussão sobre a confirmação ou não das hipóteses de Modigliani e Miller (M\&M) $(1958,1963)$ sobre a estrutura de capitais.

\section{ESTUDOS DA DÉCADA DE 80}

Alguns estudos seminais, de natureza descritiva, foram pioneiros em apresentar elementos sobre o padrão de financiamento das empresas em mercados emergentes na década de 1980. Entre eles estão os de Singh (1994), Glen e Pinto (1994) e Booth, Aivazian, Demirgüç-Kunt e Maksimovic (2001). A análise comparativa desses estudos lança mão de dados contábeis, cujos critérios e qualidade obviamente variam de país para país. De maneira geral, esses estudos mostram as empresas brasileiras usando mais lucros retidos do que capital de terceiros de longo prazo. Alguns desses estudos se apressam em concluir que as empresas brasileiras usavam mais o capital próprio do que o capital de terceiros, o que é correto, desde que se ressalve que o uso de capital próprio obtido por meio de emissão de ações não era tão comum, tendo havido alguns anos de hot issues, como 1986, na década em tela.

Booth e outros (2001) analisam empresas em 10 mercados emergentes entre 1980 e 1990: Brasil, Coréia do Sul, Índia, Jordânia, Malásia, México, Paquistão, Tailândia, Turquia e Zimbábue. Os estudos de Singh (1994) e Glen e Pinto (1994) também tratam dos mesmos países e período, são mais descritivos e apresentam conclusões similares. Essa seção se concentrará na síntese e nas implicações dos resultados apresentados por Booth e outros (2001). A Tabela 1 sumariza algumas informações compiladas a partir de alguns desses artigos. Os valores apresentados são médias aritméticas de indicadores relativos às empresas que compreendem as amostras de cada país retiradas das tabelas elaboradas por Booth e outros (2001) para os países emergentes e por Rajan e Zingales (1995) para países desenvolvidos, incluídos apenas a título de comparação.

Booth e outros (2001) procuram analisar se as decisões de financiamento são substancialmente diferentes entre os países desenvolvidos e emergentes, se os determinantes da estrutura de capital ao nível da firma são os mesmos nesses dois grupos de países e se a influência desses determinantes é reforçada mediante o uso de fatores relativos ao país na análise seccional dos dados. Essas perguntas tornaram a ser formuladas por outros pesquisadores que realizaram análises similares para períodos mais recentes ou para regiões geográficas específicas. A amostra de Booth e outros (2001) concentra-se em no máximo 100 empresas de maior porte listadas nas bolsas de cada país, apresentando, portanto, um viés em favor das empresas maiores, gerando conclusões que podem não ser generalizáveis para as empresas de menor porte ou não listadas.

Os autores analisam o comportamento do endividamento total e do endividamento de longo prazo, conforme mostra a Tabela 1. Em geral, esses estudos definem o endividamento total como a proporção entre o passivo total e a soma do passivo total mais o patrimônio líquido. Portanto, o passivo circulante, que tem características peculiares, é incluído no cálculo do endividamento total. De Jong e outros (2006) não recomendam que se analise o endividamento total, uma vez que o passivo circulante é dominado por recebíveis decorrentes da atividade, que são determinados por fatores completamente diferentes. $\mathrm{O}$ interesse maior deste artigo é o passivo de longo pra- 
Tabela 1 - Indicadores de estrutura de capitais ao nível da firma (1980-1990) Todos os valores são médias e percentuais. Para a definição das variáveis veja as notas explicativas da tabela.

\begin{tabular}{|c|c|c|c|c|c|c|c|c|c|c|c|c|}
\hline 带 & 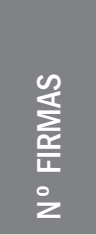 & $\begin{array}{l}\text { 을 } \\
\text { 옴 } \\
\text { 문 }\end{array}$ & 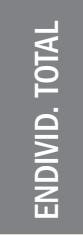 & 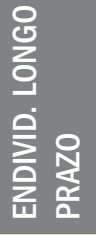 & 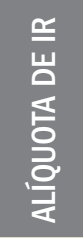 & 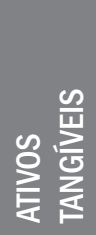 & 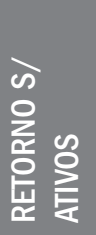 & 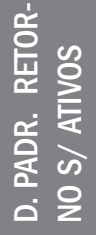 & 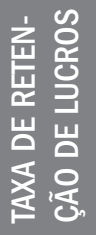 & 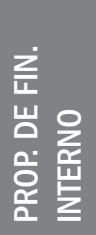 & 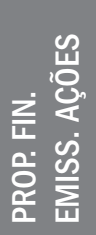 & 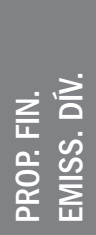 \\
\hline \multicolumn{13}{|l|}{ Países emergentes: } \\
\hline Brasil & 49 & $85-91$ & 30,3 & 9,7 & 13,9 & 67,5 & 6,7 & 9,0 & 98,3 & 46,0 & 37,2 & 5,6 \\
\hline México & 99 & $84-90 *$ & 34,7 & 13,8 & 26,3 & 32,8 & 8,1 & 5,6 & $\mathrm{~N} / \mathrm{D}$ & 23,1 & 64,7 & 1,0 \\
\hline Zimbábue & 48 & $80-88$ & 41,5 & 13,0 & 28,9 & 44,4 & 11,6 & 5,7 & 61,7 & 57,0 & 43,5 & 0,0 \\
\hline Malásia & 96 & $83-90 *$ & 41,8 & 13,1 & 32,2 & 57,6 & 6,9 & 4,5 & 51,7 & 29,7 & 48,0 & 12,0 \\
\hline Jordânia & 38 & $83-90$ & 47,0 & 11,5 & 16,3 & 47,3 & 6,8 & 7,5 & 48,0 & 54,8 & 25,5 & 5,8 \\
\hline Tailândia & 64 & $83-90$ & 49,4 & $\mathrm{~N} / \mathrm{D}$ & 28,8 & 36,0 & 13,0 & 3,4 & 48,7 & 14,7 & N/D & $\mathrm{N} / \mathrm{D}$ \\
\hline Turquia & 45 & $83-90 *$ & 59,1 & 24,2 & 29,7 & 41,1 & 9,9 & 5,5 & 37,8 & 13,4 & 66,6 & 16,9 \\
\hline Paquistão & 96 & $80-87$ & 65,6 & 26,0 & 12,4 & 38,2 & 9,4 & 6,2 & 65,9 & 67,5 & 5,2 & 23,9 \\
\hline Índia & 99 & $80-90$ & 67,1 & 34,0 & 21,8 & 41,0 & 7,1 & 4,5 & 68,0 & 38,1 & 16,3 & 38,9 \\
\hline Coréia do Sul & 93 & $80-90$ & 73,4 & 49,4 & 29,9 & 48,9 & 3,7 & 3,1 & 65,7 & 15,8 & 46,9 & 30,4 \\
\hline Média emergentes & & & 53,3 & 23,1 & 25,1 & 43,0 & 8,5 & 5,1 & 60,6 & 36,0 & 39,3 & 14,9 \\
\hline \multicolumn{13}{|l|}{ Países desenvolvidos: } \\
\hline Reino Unido & 608 & 91 & 57,8 & 29,7 & $\mathrm{~N} / \mathrm{D}$ & 45,3 & $\mathrm{~N} / \mathrm{D}$ & N/D & $\mathrm{N} / \mathrm{D}$ & N/D & $\mathrm{N} / \mathrm{D}$ & N/D \\
\hline Canadá & 318 & 91 & 60,3 & 48,4 & $\mathrm{~N} / \mathrm{D}$ & 66,8 & N/D & $\mathrm{N} / \mathrm{D}$ & $\mathrm{N} / \mathrm{D}$ & $\mathrm{N} / \mathrm{D}$ & N/D & $\mathrm{N} / \mathrm{D}$ \\
\hline EUA & 2.580 & 91 & 66,1 & 49,0 & $\mathrm{~N} / \mathrm{D}$ & 52,0 & N/D & $\mathrm{N} / \mathrm{D}$ & N/D & N/D & N/D & N/D \\
\hline Japão & 514 & 91 & 66,8 & 42,6 & $\mathrm{~N} / \mathrm{D}$ & 42,3 & $\mathrm{~N} / \mathrm{D}$ & $\mathrm{N} / \mathrm{D}$ & $\mathrm{N} / \mathrm{D}$ & $\mathrm{N} / \mathrm{D}$ & $\mathrm{N} / \mathrm{D}$ & $\mathrm{N} / \mathrm{D}$ \\
\hline Itália & 118 & 91 & 67,4 & 42,6 & $\mathrm{~N} / \mathrm{D}$ & 43,5 & N/D & $\mathrm{N} / \mathrm{D}$ & N/D & $\mathrm{N} / \mathrm{D}$ & N/D & $\mathrm{N} / \mathrm{D}$ \\
\hline França & 225 & 91 & 68,8 & 44,9 & N/D & 41,7 & N/D & $\mathrm{N} / \mathrm{D}$ & $N / D$ & $\mathrm{~N} / \mathrm{D}$ & $\mathrm{N} / \mathrm{D}$ & $\mathrm{N} / \mathrm{D}$ \\
\hline Alemanha & 191 & 91 & 72,0 & 60,0 & $\mathrm{~N} / \mathrm{D}$ & 40,6 & N/D & $\mathrm{N} / \mathrm{D}$ & $\mathrm{N} / \mathrm{D}$ & $\mathrm{N} / \mathrm{D}$ & $N / D$ & N/D \\
\hline Média desenvolvidos & & & 65,6 & 45,3 & $\mathrm{~N} / \mathrm{D}$ & 47,5 & N/D & $\mathrm{N} / \mathrm{D}$ & $\mathrm{N} / \mathrm{D}$ & N/D & $\mathrm{N} / \mathrm{D}$ & N/D \\
\hline
\end{tabular}

Fontes: As informações para mercados emergentes são médias provenientes da Tabelas I e IV de Booth e outros (2001, p. 90 e 102), exceto as proporções medianas de financiamento interno e por emissão de ações e dívida e por retenção de lucros, provenientes da Tabela 2 de Singh (1994, p. 129); as informações originais das estimativas para os mercados desenvolvidos foram calculadas pelos autores a partir do balanço padronizado agregado mostrado na Tabela II de Rajan e Zingales (1995, p. 1428).

Notas: Mercados ordenados segundo o endividamento total. "Endivid. tot." é a razão entre o endividamento total e o ativo total. "Endivid. longo prazo" é o endividamento de longo prazo definido como o endividamento total menos o passivo circulante sobre o endividamento total menos o passivo circulante mais o patrimônio líquido. O endividamento de longo prazo para os países desenvolvidos foi calculado segundo a fórmula usada por Booth e outros (2001) para os países emergentes, para efeito de comparação, a partir de dados da Tabela II de Rajan e Zingales (1995). "Taxa de retenção de lucros" é definida como o lucro líquido menos os dividendos como proporção do lucro líquido. "Prop. de fin. interno" é o percentual da mudança no ativo total financiada pela retenção de lucros. "Prop. fin. emiss. ações" é o percentual da mudança no ativo total financiada pela emissão de ações. "Prop. fin. emiss. dívida" é o percentual da mudança no ativo total financiada pela emissão de dívida. "Alíquota de IR" é a alíquota média calculada entre o lucro antes e depois de imposto de renda. "Ativos tangíveis" é a proporção de ativos tangíveis definida como o ativo total menos o ativo circulante sobre o ativo total. "Retorno s/ ativos" é o retorno sobre ativos, definido como o lucro antes de impostos dividido pelo ativo total. "D. pad. retorno s/ ativos" é o desvio padrão do retorno sobre ativos e um sub-rogado para o risco da empresa. "N/D" é não disponível.

* Os períodos para o cálculo das taxas de retenção de lucros e das proporções de financiamento interno, por ações e por dívida são diferentes para estes países, sendo 1980-1990 para o México, 1980-1988 para a Malásia e 1982-1990 para a Turquia. 
zo. Nesse caso, a proporção de endividamento de longo prazo é definida como o passivo total menos o passivo circulante dividido pelo passivo total menos o passivo circulante mais o patrimônio líquido, conforme definido por Booth e outros (2001).

$\mathrm{Na}$ análise descritiva, o Brasil fica entre os países de baixo endividamento. O nível de endividamento médio no período 1985-1991, um período de elevadas taxas de inflação no país, é de 30,3\% para o endividamento total e de $9,7 \%$ para o endividamento de longo prazo. Portanto, o primeiro fato estilizado a respeito do financiamento no Brasil pode ser: no período de inflação elevada, o nível de endividamento das empresas brasileiras era bem menor do que o observado em algumas economias emergentes de tamanho comparável e em economias desenvolvidas. Entre 1985 e 1991, a inflação observada nos países emergentes retratados na Tabela 1, bem como nos países desenvolvidos, foi menor do que a ocorrida no Brasil, embora esse tenha sido um período de inflação mais elevada no mundo.

O nível de endividamento das empresas também reflete a volatilidade do investimento registrado no período. Entre 1985 e 1991 o nível de investimento (razão entre a formação bruta de capital fixo e o PIB) apresentou valores ora muito altos, ora muito baixos, em relação à média histórica de 30 anos (20,4\% entre 1976 e 2005). Em um cenário de inflação elevada, sucessivos planos econômicos, rompimento de contratos e volatilidade de investimento, o nível de endividamento das empresas brasileiras foi bastante baixo. No mesmo período, foram registradas taxas elevadas de crescimento do PIB (cerca de $7 \%$ em 1985 e 1986), entremeadas com taxas praticamente nulas de crescimento (1988 e 1990). Portanto, o período foi de muita incerteza na economia, o que não favorece o endividamento, particularmente o de longo prazo. Além disso, a liquidez internacional à época era bem menor e a integração entre os mercados financeiros dos países emergentes com os dos países centrais ainda era baixa. Outro fato estilizado que se pode derivar dessas observações empíricas é que em períodos de grande volatilidade do investimento e incerteza econômica, mesmo nos anos em que a taxa de investimento é elevada, não há aumento do nível de endividamento de longo prazo.

De forma geral, o endividamento das empresas nas economias emergentes é menor do que o apresentado pelas empresas nas economias desenvolvidas na década de 1980. Outro fato interessante é que a diferença entre o endividamento total e o de longo prazo é mais pronunciada entre as economias emergentes do que entre as de- senvolvidas, sugerindo a maior dificuldade das empresas nesses países de obter financiamento de longo prazo. As possíveis razões são exploradas mais adiante.

Analisando os dados na Tabela 1, vemos que a taxa de retenção de lucros no Brasil é a maior dos 10 mercados emergentes. De fato, o Brasil apresenta uma taxa de retenção próxima dos $100 \%$ no período, sugerindo que o financiamento junto a bancos ou ao mercado de capitais era diminuto durante esse período de alta inflação. Pela tabela, pode-se ver que o financiamento do crescimento dos ativos líquidos deve-se, na maior parte, à retenção de lucros, depois ao financiamento via ações e, por último, ao financiamento via dívida de longo prazo. O financiamento dos ativos líquidos por retenção é maior do que a média dos 10 países emergentes analisados, enquanto o financiamento externo à empresa, seja por dívida ou ações, é menor que a média.

Booth e outros (2001) analisam os determinantes da estrutura de capital relativos à firma, controlando-os para efeitos ao nível dos países e dos setores de atividades. Como as condições institucionais variam muito entre os diversos países, é possível que os determinantes da decisão sobre a estrutura de capital variem muito também. Algumas das variáveis relativas à firma apresentam um comportamento mais uniforme do que outras. A lucratividade (retorno sobre ativos) relaciona-se negativamente com o endividamento. Outras variáveis, como a alíquota de imposto, a proporção de ativos tangíveis, o risco do negócio e a relação entre o valor de mercado e o valor contábil dos ativos não apresentam comportamento consistente e significativo na maioria dos casos, indicando que a situação em cada país pode diferir bastante, levando a influências diferentes desses fatores em cada país. No caso do Brasil, o nível de endividamento de longo prazo varia negativa e significativamente com a proporção de ativos tangíveis, com o risco de negócios e com a lucratividade, e positiva e significativamente com o tamanho da empresa. Booth e outros (2001) concluem que os fatores que determinam o nível de endividamento nos países emergentes, em geral, são similares aos fatores que ocorrem nos países desenvolvidos, mas, algumas vezes, seus sinais são contraditórios. Eles atribuem esse conflito à maior dependência dos passivos circulantes por parte dos países emergentes, cujos determinantes podem ser diferentes dos determinantes do passivo de longo prazo.

Booth e outros (2001) analisam alguns elementos institucionais e macroeconômicos no período, que são suas variáveis relativas ao país. O grau de desenvolvimento do mercado de ações, segundo diversos tipos de medida, 
parece estar positivamente relacionado com o nível de financiamento via ações e negativamente relacionado com o financiamento via títulos de dívida de longo e de curto prazo. Da mesma forma, o grau de desenvolvimento do mercado bancário também parece estar relacionado com o volume de emissões de títulos de dívida corporativa. O crescimento econômico real influencia positivamente a taxa de endividamento e a inflação a influencia negativamente. O nível de endividamento parece ser maior onde a tributação é maior, ou seja, onde a vantagem tributária da dívida é maior.

Finalmente, Booth e outros (2001) fazem uma análise do poder explicativo comparativo das variáveis que indicam o país de origem e das variáveis relativas à firma e concluem que as variáveis relativas ao país explicam uma proporção um pouco maior da variância do endividamento total do que as variáveis da firma. Por outro lado, dependendo do modelo, essas variáveis explicam tanto ou mais que as variáveis mudas de país de origem considerando o endividamento de longo prazo. Portanto, um fato estilizado que se pode derivar é que as características institucionais e macroeconômicas de um país são elementos importantes para explicar a decisão de financiamento das empresas, sem que isso signifique que se devam descartar determinantes dessa decisão ao nível da firma.

Tomando como base a teoria originalmente desenvolvida por M\&M $(1958,1963)$, a relação negativa da lucratividade com nível de endividamento não é consistente com as implicações de M\&M (1963). Já a relação positiva do tamanho com o nível de endividamento é consistente com a hipótese de menores riscos de dificuldades financeiras na teoria das compensações desenvolvida por M\&M (1963). A evidência sobre endividamento maior onde a vantagem tributária é maior também é consistente com as hipóteses de MM. Portanto, os testes de Booth e outros (2001) apresentam evidências apenas parciais que sustentam as hipóteses de M\&M em mercados emergentes.

A próxima seção retoma essa questão por meio de estudos mais recentes, que atribuem peso maior às variáveis relativas à firma do que às variáveis relativas ao país, sem considerar que essas sejam irrelevantes.

\section{ESTUDOS RECENTES}

Esta seção examina artigos que lidam com períodos mais recentes, sempre com amostras bem maiores, tanto no número de países quanto na representatividade da amostra de cada país. Em alguns desses estudos ainda pode haver o problema do viés para as maiores empresas de capital aberto listadas em bolsa. Os estudos revistos incluem De Jong, Kabir e Nguyen (2006), Jalal (2007), Glen e Singh (2004) e Fan, Titman e Twite (2006), com menções ocasionais a outros estudos recentes. Com a exceção do estudo de Glen e Singh (2004), que é mais descritivo, todos os demais experimentam modelos que incluem variáveis relativas ao país, do setor de atividade e da firma. De forma geral, pode-se antecipar que estar sediada em certo país é um elemento importante para explicar a decisão de estrutura de capitais de uma empresa.

A seção inicia-se com uma análise descritiva, onde se procura verificar o comportamento do nível de endividamento. A seguir se passa à análise das variáveis do país. Nessa parte, procurou-se resumir diversas métricas a respeito das instituições e do comportamento macroeconômico dos países para sustentar a discussão. Finalmente, contempla-se o resultado de modelos que incluem tanto os determinantes da estrutura de capital ao nível da firma quanto os fatores do país e as variáveis mudas do setor de atividade.

Em termos do comportamento do nível de endividamento e de outras variáveis ao nível da firma, a Tabela 2 apresenta algumas características comparativas do Brasil com outros países. A tabela foi elaborada a partir de informações compiladas do artigo de De Jong e outros (2006) e apresenta médias para variáveis selecionadas para alguns grupos de países. Embora a fórmula de cálculo do nível de endividamento nas Tabelas 1 e 2 não seja a mesma, aparentemente o nível de endividamento de longo prazo cresceu no Brasil no período mais recente. As empresas brasileiras incluídas na amostra de De Jong e outros (2006) são na média maiores que as empresas médias dos demais grupos de países, indicando que somente as maiores empresas listadas devem ter sido consideradas, pois o Brasil conta com 101 empresas na amostra. Essas empresas brasileiras apresentam um nível de endividamento de longo prazo maior do que a média da maioria dos grupos de países mostrados na Tabela 2, com uma alíquota média de impostos menor do que a maioria dos grupos de países. Por outro lado, os indicadores para oportunidades de crescimento e de liquidez das empresas brasileiras na amostra estão entre os mais baixos quando comparados às médias dos grupos de países. O retorno sobre os ativos e o desvio padrão do EBITDA apresentam valores intermediários em relação às médias de grupos de países.

Glen e Singh (2004) têm como objetivo estabelecer 
fatos estilizados a respeito de indicadores contábeis de empresas em países emergentes e desenvolvidos. Eles analisaram quase 8 mil empresas de 44 países no período entre 1994 e 2000 visando entender o impacto dos fatores relativos ao país e do setor de atividade sobre o comportamento das variáveis contábeis da empresa disponíveis. Uma variável importante na análise seccional em finanças corporativas é o tamanho da empresa. Glen e Singh (2004) se preocupam em verificar se ela se comporta de forma diferente nos países emergentes e desenvolvidos. A conclusão é que a distribuição, em sua parte central, é similar, e que a diferença entre as distribuições está nos extremos, havendo mais firmas muito grandes na amostra dos países desenvolvidos e mais firmas muito pequenas para o tipo de amostra em questão - nos países emergentes. Assim, para a maior parte da amostra, as distribuições são similares.

Da mesma forma que nos estudos mais antigos, Glen

Tabela 2 - Indicadores de estrutura de capitais ao nível da firma (1997-2001)

Para a definição das variáveis veja as notas explicativas da tabela.

\begin{tabular}{|c|c|c|c|c|c|c|c|c|c|c|c|}
\hline 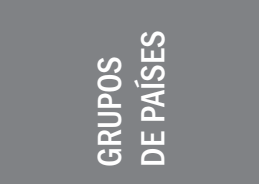 & 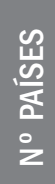 & 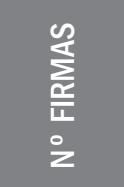 & 商商 & 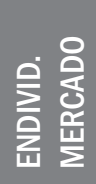 & 芯 & 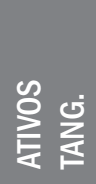 & 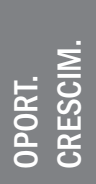 & $\sum^{\frac{1}{2}}$ & 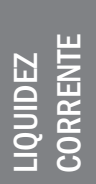 & 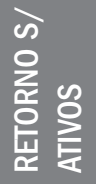 & 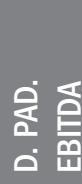 \\
\hline Todos & 42 & 11.849 & 13,94 & 12,86 & 26,59 & 39,38 & 1,80 & 5,029 & 2,22 & 9,94 & 5,53 \\
\hline Desenvolvidos & 22 & 9.685 & 14,55 & 11,64 & 25,33 & 33,13 & 1,99 & 5,359 & 2,34 & 8,88 & 6,20 \\
\hline Emergentes & 20 & 2.164 & 13,28 & 14,21 & 27,97 & 46,25 & 1,61 & 4,667 & 2,09 & 11,11 & 4,79 \\
\hline $\begin{array}{l}\text { Europeus } \\
\text { desenvolvidos }\end{array}$ & 16 & 3.204 & 14,05 & 11,13 & 25,27 & 31,22 & 2,05 & 5,522 & 2,34 & 9,36 & 5,88 \\
\hline $\begin{array}{l}\text { Europeus } \\
\text { emergentes }\end{array}$ & 4 & 90 & 8,45 & 8,33 & 25,60 & 46,98 & 1,69 & 4,273 & 2,01 & 15,80 & 4,80 \\
\hline Ásia - emergentes & 8 & 1.511 & 13,14 & 14,15 & 38,29 & 41,15 & 1,88 & 5,274 & 2,45 & 7,85 & 5,74 \\
\hline Japão e Cingapura & 2 & 3.230 & 10,50 & 10,05 & 28,94 & 33,40 & 1,32 & 4,075 & 1,84 & 7,30 & 4,05 \\
\hline Canadá e EUA & 2 & 2.950 & 19,40 & 14,70 & 24,16 & 37,10 & 2,35 & 5,590 & 3,01 & 7,25 & 8,30 \\
\hline América Latina & 5 & 191 & 14,40 & 16,52 & 19,11 & 53,48 & 1,25 & 4,756 & 1,94 & 10,90 & 3,26 \\
\hline $\begin{array}{l}\text { Austrália e } \\
\text { N. Zelândia }\end{array}$ & 2 & 301 & 17,70 & 14,25 & 23,47 & 44,20 & 1,75 & 5,105 & 2,20 & 8,20 & 8,85 \\
\hline Índia e Paquistão & 2 & 271 & 19,15 & 19,40 & 16,55 & 46,00 & 1,56 & 1,720 & 1,57 & 14,90 & 4,95 \\
\hline Brasil & 1 & 101 & 16,40 & 16,20 & 22,07 & 48,50 & 0,95 & 6,840 & 1,30 & 11,80 & 4,40 \\
\hline
\end{tabular}

Fontes: Médias calculadas pelos autores a partir de médias para países da região exibidas na Tabela 1 de De Jong e outros (2006, p. 34). A fonte original dos dados empregados por De Jong e outros (2006) é o Compustat Global. Os países desenvolvidos analisados por De Jong e outros (2006) são: Alemanha, Austrália, Áustria, Bélgica, Canadá, Cingapura, Dinamarca, Espanha, EUA, Finlândia, França, Grécia, Holanda, Irlanda, Itália, Japão, Nova Zelândia, Noruega, Portugal, Reino Unido, Suécia e Suíça. Os países emergentes analisados por De Jong e outros (2006) são: Argentina, Brasil, Chile, China, Colômbia, Coréia do Sul, Croácia, Filipinas, Hong Cong, Hungria, Índia, Indonésia, Malásia, México, Paquistão, Peru, Polônia, Tailândia, Taiwan e Turquia. Europeus emergentes: Croácia, Hungria, Polônia e Turquia.

Notas: "Endivid. contábil" é o endividamento contábil definido como o endividamento de longo prazo sobre o ativo contábil total. "Endivid. mercado" é o endividamento a valores de mercado, definido como o endividamento de longo prazo dividido pelo ativo a valores de mercado, definido como o ativo contábil menos o patrimônio líquido contábil mais o patrimônio líquido a valores de mercado. "Alíquota de IR" é a alíquota média de impostos de cada ano. "Ativos tang." são definidos como ativos permanentes divididos pelo ativo total. "Oport. crescim." são as oportunidades de crescimento, definidas como o valor de mercado do ativo total dividido pelo valor contábil do ativo total. "Tamanho" é definido como o logaritmo natural da receita total. "Liquidez corrente" é definida como a razão entre o ativo circulante e o passivo circulante. "Retorno s/ ativos" é o EBTIDA sobre o ativo total. "D. pad. EBITDA" é o desvio padrão do EBTIDA durante o período e representa o risco da firma. 
e Singh (2004) concluem que as empresas em economias emergentes usam menos dívida de longo prazo do que aquelas sediadas em mercados desenvolvidos. Eles constatam que o nível de endividamento está caindo com o tempo nas economias emergentes. Para esse período, nos diversos trabalhos examinados, o poder explicativo dos fatores da firma é claramente maior que o dos fatores do país, sem que estes últimos deixem de ter importância. Os fatores do setor de atividades, entretanto, têm importância menor. Embora o grau explicativo do setor de atividade seja semelhante entre os países emergentes e desenvolvidos, ele explica muito menos do que o país de origem. Isso é constatado por Terra (2002) e Jorgensen e Terra (2003) para uma amostra de empresas de sete países latino-americanos entre 1986 e 2000, para um conjunto de variáveis mudas de país e alguns fatores macroeconômicos. Eles também constatam que os fatores relativos ao país predominam sobre os fatores macroeconômicos e variáveis mudas identificando o país de origem. Os autores alegam que não há confirmação para os resultados de Booth e outros (2001) na América Latina, mas suas conclusões devem ser comparadas com cautela, porque pode ser que as grandes semelhanças, mais do que as diferenças, entre os países de uma mesma região tenham influenciado seus resultados. Além disso, como o autor inclui tanto o período mais recente quanto parte do mais antigo na amostra, seus resultados podem tender a ser consistentes com os do período maior. Ainda para a América Latina, Perobelli e Famá (2003) alegam que os fatores determinantes da estrutura de capital da firma variam de país para país, como é usual nas análises feitas individualmente para os países da amostra, mas não empregam fatores do país para fazerem uma comparação de seu poder explicativo em relação às variáveis da firma. Barros, Da Silveira e Famá (2004) também analisam empresas latino-americanas, mas igualmente não empregam fatores do país além dos determinantes da firma. Aggarwal e Baliga (1987) examinam uma amostra de 230 empresas provenientes de 22 países da América Latina e constatam a importância maior de fatores relativos ao país, porém eles empregam apenas o tamanho da empresa como variável da firma e uma amostra dos anos 1980.

Ao examinar os níveis de endividamento total, Glen e Singh (2004) constatam que eles eram maiores nos mercados emergentes, mas estão em declínio durante o período, tornando-se menores ao final do período de análise (mediana de $49 \%$ para os emergentes contra $52 \%$ para os desenvolvidos em 2000). O endividamento total maior nos mercados emergentes pode indicar o papel mais preponderante do passivo circulante nessas economias. Ao examinar o endividamento excluindo o passivo circulante, eles constatam que ele também declina no período, com uma mediana de $13 \%$ para os mercados emergentes e de $16 \%$ para os desenvolvidos em 2000, consistentemente com os dados de De Jong e outros (2006). Portanto, as empresas em economias emergentes usam muito mais o passivo circulante e menos o passivo de longo prazo do que as empresas em países desenvolvidos. Os autores também constatam que empresas maiores apresentam endividamento mais alto, o que é verificado por outros autores para esse período e períodos anteriores. Considerando-se o passivo total em relação ao valor de mercado da firma, para Fan e outros (2006), o Brasil, mais uma vez, aparece entre os países com maior endividamento total como proporção do valor de mercado da firma (mediana de $47 \%$ ) e os países em desenvolvimento também apresentam maior endividamento total (mediana de $27 \%$ ) do que as empresas em países desenvolvidos (mediana de 22\%). Quando Fan e outros (2006) consideram somente o endividamento de longo prazo, as coisas mudam. O Brasil aparece com um endividamento de longo prazo mediano, como proporção do endividamento total, e não do valor de mercado da firma, de $51 \%$, para uma mediana dos emergentes, em geral, de $46 \%$ e, para os desenvolvidos, de $64 \%$.

No caso do Brasil, Glen e Singh (2004) mostram que a mediana do endividamento total variou entre $42 \%$ em 1995, para as 31 companhias analisadas, e 62\% em 2000, para as 117. Já o nível de endividamento mediano de longo prazo, excluindo o passivo circulante, variou entre $17 \%$ em 1995 e $25 \%$ em 2000. Portanto, o passivo circulante mediano, por diferença, variou entre $25 \%$ e $37 \%$ no período. Com a estabilização econômica, o uso de capital de terceiros aumentou, tanto na forma de passivo circulante quanto nas demais formas. O comportamento mediano do Brasil está em oposição ao da maioria dos mercados emergentes, provavelmente um efeito da inflação mais baixa no Brasil e, talvez, dos efeitos posteriores à crise da Ásia nos países asiáticos. Para os EUA, por exemplo, a mediana do endividamento não circulante era de 13\% em 2000. Portanto, ou as empresas brasileiras usam mais o endividamento de longo prazo do que as estadunidenses ou o ativo das empresas brasileiras que aparecem no balanço se encontra significativamente depreciado em relação ao das empresas dos EUA, talvez ainda consequêencia do período de elevada inflação, ou talvez porque o patrimônio líquido em relação ao ativo total das empresas nos países desenvolvidos seja bem maior do que o patrimônio líquido das empresas brasi- 
leiras. O patrimônio líquido pequeno no Brasil não seria surpresa uma vez que o financiamento por meio de ações não era fácil nem barato (ROCCA, SILVA e CARVALHO, 1998; LEAL, 2004). Na Tabela 2, podemos ver que o endividamento médio de longo prazo das empresas de capital aberto no Brasil é maior do que a média dos países desenvolvidos, emergentes e europeus. Como é difícil acreditar que, em um mercado onde o endividamento de longo prazo é difícil e disponível para um conjunto relativamente pequeno de empresas, as empresas o consigam em maior abundância do que nos EUA, deve-se suspeitar dos resultados apresentados por Glen e Singh (2004) para o Brasil. Ou os números são representativos apenas de um pequeno conjunto de empresas, o que é verdadeiro, ou o patrimônio líquido das empresas brasileiras é menor porque o valor contábil de suas ações e o volume de financiamento via mercado de ações é menor, o que possivelmente também é verdade, pois a relação do valor de mercado sobre o valor contábil da ação das empresas brasileiras era muito baixo até recentemente (STANDARD \& POORS, 2007).

De Jong e outros (2006) também analisam um grande conjunto de 42 países emergentes e desenvolvidos no período compreendido entre 1997 e 2001, visando verificar o impacto de fatores da firma e do país como determinantes da estrutura de capitais das empresas. Além disso, eles investigam se os fatores do país, além de afetarem a estrutura de capitais diretamente, afetam-na por meio de sua influência sobre os determinantes locais da estrutura de capitais, de forma indireta, e, de fato, demonstram que isso acontece. Portanto, a importância dos fatores do país é ainda maior, uma vez que afetam a estrutura de capitais direta e indiretamente. Os autores também alegam que estudos anteriores supõem que o efeito dos fatores da firma afeta com a mesma intensidade a estrutura de capitais dos diversos países analisados, ao passo que isso não é verdadeiro, porque esse impacto pode ser intensificado ou atenuado pela influência dos fatores do país sobre os fatores locais da firma.

Um elemento macro interessante é a sincronia do financiamento com o ciclo econômico. Korajczyk e Levy (2003), para os EUA, sugerem que empresas sem restrições de financiamento atuam de maneira contracíclica, isto é, emitem menos dívidas quando o crescimento econômico é maior. Uma explicação oferecida pelos autores seria a remuneração dos executivos, que é menor quando o retorno do mercado de ações é menor, levando-os a preferir a emissão de dívidas, que mitigam os problemas de agência. Por outro lado, a maioria das empresas teria restrições de financiamento, e preferem aumentar o nível de endividamento quando os retornos do mercado de ações e o crescimento econômico são maiores. Seria mais fácil tomar empréstimos quando a lucratividade da empresa é maior. Ao se extrapolarem essas conclusões para os mercados emergentes, onde a maioria das empresas deve sofrer sérias restrições ao financiamento, pode-se oferecer mais um fato estilizado: onde as empresas sofrem restrições de financiamento, o endividamento aumenta com o crescimento econômico, que é sustentado pelo que se observa nos trabalhos de Booth e outros (2001) e De Jong e outros (2006).

De Jong e outros (2006) examinam os fatores relativos às firmas e concluem que empresas maiores e com mais ativos tangíveis tendem a apresentar mais endividamento de longo prazo, e que a rentabilidade mantém uma relação negativa com esse nível de endividamento para a maioria dos países. As demais variáveis examinadas não apresentaram resultados claros. Os autores encontram sustentação para corroborar estudos anteriores em que esses fatores da firma afetam a decisão sobre a estrutura de capital na forma preconizada pela teoria e que essas teorias têm a capacidade de explicar a escolha sobre a estrutura de capitais em vários países. Entretanto, eles não aceitam a hipótese de que os coeficientes do impacto de cada um deles sejam iguais para todos os países.

Sobre os fatores referentes ao país, De Jong e outros (2006) indicam, como em outros estudos, que o crescimento econômico, a taxa de inflação, a abertura comercial e o ambiente legal influenciam a estrutura de capitais dos países e que o poder explicativo desses fatores, controlado para os fatores da firma, é considerável. Um fato estilizado que se deriva dos resultados de De Jong e outros (2006) é que, em países com economia mais estável (maior crescimento e menor inflação) e com melhor cumprimento das leis, as empresas não somente contraem mais dívidas, como alguns determinantes da estrutura de capitais têm seus efeitos realçados.

Fan e outros (2006) também estudam os determinantes da estrutura de capitais de 23.192 empresas de 39 países, emergentes e desenvolvidos, no período entre 1991 e 2000. Como nos demais estudos, as empresas listadas de capital aberto predominam. Eles procuram distinguir fatores que influenciam o endividamento de curto e de longo prazo, além de empregar uma grande quantidade de fatores ao nível dos países. Outra inovação é que os autores analisam as interações entre fatores de países. Em consonância com outros estudos, os autores concluem que os fatores ao nível da firma oferecem o maior poder explicativo, seguidos dos fatores ao nível do país, que são mais importantes do que o setor de atividades da 
firma. Entre os fatores ao nível do país empregados, estão o nível de tributação, métricas para a qualidade das instituições legais e financeiras, assim como medidas de desenvolvimento econômico e de inflação.

Em relação ao país, um dado novo trazido por Fan e outros (2006) é que o nível de endividamento é menor em países onde o tratamento tributário dos dividendos é mais favorável. O mercado de trabalho raramente é incluído entre os fatores de país. Fan e outros (2006) empregam um sub-rogado para o poder dos sindicatos e concluem que o endividamento é maior onde os sindicatos são mais fortes. Uma explicação oferecida é que o endividamento é empregado como elemento de barganha pela firma nas negociações com os sindicatos, como um fator que ameaça a existência da firma e do emprego. Outro elemento relativo ao país considerado pelos autores são os montantes relativos de depósitos bancários. Em países onde eles são maiores, há mais endividamento de curto prazo. Além disso, em países onde o estado controla mais bancos, as empresas tendem a ser mais endividadas a longo prazo, o que é interpretado pelos autores como um possível uso maior de subsídios ou como um "capitalismo de compadres". Seguindo com esses fatores e consistentemente com outros autores, o endividamento de longo prazo é maior onde o sistema jurídico é menos viciado e mais empregado para a resolução de conflitos. Ao analisar a influência de medidas de corrupção, os autores concluem que firmas em países mais corruptos ou sistemas legais mais frágeis usam mais endividamento de curto prazo e são mais endividadas de forma geral. Por outro lado, empresas de países de tradição jurídica de direito consuetudinário usam mais o endividamento de longo prazo e são menos endividadas em geral. Entretanto, se os países com essa tradição jurídica são mais corruptos, os possíveis efeitos positivos do direito consuetudinário desaparecem.

Da discussão acima, podemos derivar alguns fatos estilizados. Assim, o poder explicativo das variáveis ao nível da firma é maior do que o dos fatores ao nível do país, que por sua vez explicam mais do que os fatores sobre o setor de atividade da empresa. Os fatores de país, pelo menos, não devem ser descartados em um estudo seccional de diversos países. Outro fato estilizado que podemos derivar é que quanto maior for a corrupção e menor for o grau de aplicação das leis, maior será o endividamento de curto prazo e menor o uso de endividamento via mercado de capitais e de emissões de ações.

Céspedes, González e Molina (2008) estudam a influência da concentração de controle sobre a estrutura de capitais de 806 empresas provenientes das sete maiores economias da América Latina entre 1996 e 2005. Além do emprego de uma medida Herfindahl de concentração de controle obtida das participações diretas dos maiores acionistas no banco de dados Economática, os autores empregam algumas variáveis relativas à firma em sua análise, mas nenhuma variável do país nem do setor. Os autores alegam haver uma relação de maior endividamento quando o grau de concentração é maior. Entretanto, quando seus resultados são examinados para cada país isoladamente, a conclusão não se sustenta para todos os países, sugerindo que os fatores do país, omitidos por Céspedes, Gonzáles e Molina (2008), sejam importantes. Cheng e Shiu (2007) confirmam que a maior proteção ao crédito parece estar associada ao maior endividamento, e a melhor proteção ao investidor parece estar associada ao maior uso de financiamento via ações, em uma amostra de empresas provenientes de 45 países, emergentes e desenvolvidos. Esses estudos ajudam a sustentar a noção de que a maior proteção aos investidores e credores em geral está associada ao maior uso de endividamento.

Assim como em outros estudos, Fan e outros (2006) concluem que os determinantes da estrutura de capitais são razoavelmente consistentes entre os países, mas algumas diferenças não deixam de ser observadas. A rentabilidade contábil está negativamente relacionada com o endividamento, como constatado em vários estudos anteriores, mas sua influência sobre a estrutura de capitais tende a enfraquecer em função de menores incentivos tributários para a retenção de lucros em países desenvolvidos, porém se fortalece em países mais corruptos. Possivelmente, empresas de países mais corruptos se esquivam de praticar uma taxa de pagamento de dividendos maior porque o financiamento por meio da emissão de ações pode ser mais difícil ou caro, aparentemente devido à pior proteção legal aos investidores. A proporção de ativos tangíveis e o tamanho da firma se apresentaram positivamente relacionados com o endividamento total das firmas. Mais uma vez, esses resultados sustentam parcialmente as hipóteses levantadas por MM $(1958,1963)$, porque empresas mais rentáveis apresentam, consistentemente nos diversos estudos, endividamento menor, o que é contrário ao papel atribuído aos benefícios fiscais por MM. Por outro lado, o nível de tributação e fatores relativos à firma que podem estar correlacionados ao menor risco de dificuldades financeiras estão relacionados com o maior endividamento das empresas.

Fan e outros (2006) estudam explicitamente o efeito dos fatores de países sobre o prazo de vencimento da dívida. O prazo é significativamente menor em países mais corruptos com mais depósitos bancários, e em paí- 
ses desenvolvidos com maior controle estatal sobre os bancos. Por outro lado, o prazo de vencimento da dívida é significativamente maior nos países com tradição de direito consuetudinário e nos países em desenvolvimento com maior controle estatal sobre os bancos. De forma geral, o prazo da dívida é maior onde a economia é mais desenvolvida. Fan e outros (2006) não encontram uma relação entre o prazo de vencimento da dívida e a taxa de inflação, ao contrário de outros estudos. Este último resultado, que à primeira vista parece intrigante, é interpretado por Fan e outros (2006) como função do período analisado. No período mais recente, as taxas de inflação declinaram significativamente na maioria dos países, deixando de ser um fator com capacidade explicativa na análise seccional da amostra global de endividamento corporativo. Portanto, um fato estilizado sobre o prazo da dívida que pode ser derivado dos resultados de Fan e outros (2006) é que ele aumenta onde o grau de desenvolvimento do mercado financeiro e da economia em geral é maior, onde a dominância dos bancos é menor e onde o grau de aplicação das leis é melhor.

Em relação aos fatores que diferenciam os países quanto à estrutura de capitais, um estudo inovador é o de Jalal (2007). O autor emprega um modelo explicativo do nível marginal de endividamento em função das necessidades externas de financiamento das empresas e interpreta o coeficiente derivado desse modelo como um indicador do grau de eficiência do mercado financeiro do país. Quanto mais próximo de 1 for o coeficiente, mais as necessidades externas de financiamento são atendidas por meio da emissão marginal de dívida. O Brasil aparece com o maior coeficiente de todos os países analisados, $0,24, \mathrm{e}$, portanto, segundo a interpretação dada por Jalal (2007), com o mercado de ações menos eficaz entre os 38 países analisados no período entre 1980 e 2005. Certamente, esse resultado tão desfavorável para o país deve muito ao período de grande instabilidade dos anos 1980. Esse coeficiente mantém uma correlação consistente com diversos indicadores do grau de desenvolvimento, qualidade das instituições e do mercado financeiro dos países.

O estudo de Jalal (2007) inclui somente as maiores empresas na amostra, como é praxe. À medida que o mercado de ações se desenvolve e é mais empregado pelas empresas, o autor constata menos uso do endividamento de forma relativa. O desenvolvimento do mercado de ações está associado ao maior desenvolvimento econômico, ao maior grau de proteção aos acionistas e ao menor grau explicativo das necessidades de financiamento externo sobre o endividamento marginal. Por outro lado, onde o mercado bancário é relativamente maior e as taxas de inflação são mais elevadas, o poder explicativo das necessidades externas de financiamento sobre a emissão marginal de dívida é maior. A inflação apresenta um comportamento não linear. A emissão marginal de dívida diminui quando a inflação é muito baixa ou muito alta. Para valores intermediários de inflação, há uma relação positiva com a emissão marginal de dívida. De forma geral, onde há fatores políticos, econômicos ou legais que complicam o desenvolvimento do mercado de ações é onde há maior nível de endividamento marginal.

Um dado muito interessante a respeito da emissão de ações e de dívida apresentado por Jalal (2007) é que, em 2004, 45\% das empresas emitiram ações de forma líquida, enquanto somente $32 \%$ emitiram dívida de forma líquida. Entretanto, quando se examina esse dado separando as firmas de países emergentes e desenvolvidos, o quadro muda. Assim, 50\% das empresas dos países desenvolvidos foram emissoras líquidas de ações, enquanto somente $30 \%$ delas foram emissoras líquidas de dívida. Já nos países emergentes, 43\% das firmas foram emissoras líquidas de dívida e somente $30 \%$ foram emissoras líquidas de ações. Portanto, o nível de endividamento marginal tem alta relação com o nível de desenvolvimento do país e, conseqüentemente, com a qualidade de suas instituições, a estabilidade da economia e outros fatores ao nível do país. Sendo assim, não é surpresa que o coeficiente do modelo estimado por Jalal (2007) seja mais elevado para os países de menor renda per capita e menor para os países de maior renda. Quanto maior for esse coeficiente, menor o grau de desenvolvimento do mercado de ações e menor o grau de emissões líquidas de ações por parte das empresas desses países.

Finalmente, cabe destacar o trabalho de Mitton (2006), que faz uma análise da evolução do endividamento em 34 mercados emergentes entre 1980 e 2004 , incluindo mais de 11 mil empresas em sua amostra. O autor conclui que o endividamento nos mercados emergentes vem aumentando, como já havia sido constatado por outros estudos revistos aqui. O autor explora algumas razões relativas aos países para esse aumento do endividamento nos mercados emergentes e conclui que os fatores da firma usualmente empregados nos estudos apresentaram uma dinâmica favorável ao aumento do endividamento, tais como maior tamanho da firma e tangibilidade de seus ativos. Do ponto de vista dos fatores de país, o autor atribui o aumento da oferta de recursos para o endividamento à globalização financeira e não ao desenvolvimento específico dos países. 


\section{CONCLUSÃO}

Este artigo sintetiza fatos estilizados sobre a estrutura de capitais de empresas de mercados emergentes privilegiando a análise de artigos que empregam amostras seccionais incluindo diversos países. Em períodos de grande volatilidade do investimento e de incerteza econômica, mesmo episódios de taxa de investimento elevada não induzem o aumento do nível de endividamento de longo prazo. O nível de endividamento de longo prazo relativo nas economias emergentes é ligeiramente maior do que nas economias em desenvolvidas, mas vem caindo como reflexo do maior emprego e atratividade do mercado de ações. A diferença entre o endividamento total e o de longo prazo é mais pronunciada entre as economias emergentes do que entre as desenvolvidas, denotando o maior uso do passivo circulante nos mercados emergentes.

O poder explicativo das variáveis relativas à firma é maior do que o dos fatores do país, que por sua vez explicam mais do que os fatores sobre o setor de atividade da empresa, porém, os fatores de país não devem ser descartados em um estudo seccional de diversos países. Em países com economia mais estável (maior crescimento e menor inflação) e com melhor cumprimento das leis, as empresas não somente contraem mais dívidas, como também alguns determinantes da estrutura de capitais têm seus efeitos realçados. Os fatores do país influenciam os fatores da firma. Um maior grau de desenvolvimento e de qualidade institucional de um país pode influenciar tanto o maior grau de endividamento de longo prazo das empresas maiores quanto das empresas menores, as primeiras usando mais o mercado de capitais e as outras mais o mercado de crédito bancário. Onde há maior proteção ao crédito há mais empréstimos para empresas com menos ativos tangíveis, e maior é o prazo da dívida. Contudo, quanto maior for a corrupção e menor for o grau de aplicação das leis, maior será o endividamento de curto prazo e menor o uso de endividamento via mercado de capitais e de emissões de ações. O nível de endividamento é menor em países onde o tratamento tributário dos dividendos é mais favorável e é maior onde os sindicatos são mais fortes.

Entre os determinantes relativos à firma, verifica-se que empresas maiores e com mais ativos tangíveis tendem a apresentar mais endividamento de longo prazo e que a rentabilidade mantém uma relação negativa com o nível de endividamento de longo prazo. Outros determinantes da firma não apresentam resultados consistentes entre os países. A evidência dos mercados emergentes apresenta sustentação apenas parcial para as proposições de MM (1958, 1963), uma vez que consistentemente as empresas mais rentáveis, que deveriam procurar mais os benefícios fiscais do endividamento, não parecem fazê-lo. Por outro lado, as empresas com menor risco de dificuldades financeiras parecem realmente se endividar mais.

\section{REFERÊNCIAS}

AGGARWAL, R; BALIGA, G. Capital structure among Latin American companies. Managerial Finance, v. 13, n. 1, p. 3-11, 1987.

BARROS, L; DA SILVEIRA, A; FAMÁ, R. Does capital structure matter? Revisiting Modigliani and Miller's empirical work using Latin American and North American data. Latin American Business Review, v. 5, n. 3, p. 43-64, 2005.

BOOTH, L; AIVAZIAN, V; DEMIRGÜÇ-KUNT, A; MAKSIMOVIC, V. Capital structures in developing countries. Journal of Finance, v. 56, n. 1, p. $87-130,2001$.

CÉSPEDES, J, GONZÁLEZ, M; MOLINA, C. Ownership Concentration and the Determinants of Capital Structure in Latin America. IESA working paper, 2008. Disponível em http://www.fma2.org/Texas/Papers/ CespedesGonzalezMolinaFMA.pdf. Acesso em 12.07.2008.

CHENG, S; SHIU, C. Investor protection and capital structure: international evidence. Journal of Multinational Financial Management, v. 17, n. 1, p. 30-44, 2007.

DE JONG, A; KABIR, R; NGUYEN, T. Capital Structure Around the World: The Roles of Firm- and Country-Specific Determinants. Erasmus University working paper, Rotterdam, Netherlands, 2006. Disponível em http://ssrn. com/abstract $=890525$. Acesso em 27.02.2008.

FAN, J; TITMAN, S; TWITE, G. An International Comparison of Capital Structures and Debt Maturity Choices. Working paper, 2006. Disponível em http://ssrn.com/abstract=423483. Acesso em 27.02.2008.

GLEN, J; PINTO, B. Debt or equity? How Firms in Developing Countries Choose. Discussion paper 22. Washington, DC: International Finance Corporation, 1994.

GLEN, J; SINGH, A. Comparing capital structures and rates of return in developed and emerging markets. Emerging Markets Review, v. 5, n. 2, p. 161-192, 2004

IFC. Emerging Stock Markets Factbook. Washington, DC: International Finance Corporation, 1992.

JALAL, A. The Pecking Order, Information Asymmetry, and Financial Market Efficiency. University of Minnesota working paper, 2007. Disponível em http://ssrn.com/abstract=939588. Acesso em 27.02.2008. 
JORGENSEN, J; TERRA, P. Determinants of capital structure in Latin America: the role of firm-specific and macroeconomic factors. In: Tenth Annual Conference of the Multinational Finance Society, 10., 2003, Montreal. Anais... Montreal: Multinational Finance Society, 2003. p. $1-48$.

KORAJCZYK, R; LEVY, A. Capital structure choice: macroeconomic conditions and financial constraints. Journal of Financial Economics, v. 68, n. 1, p. 75-109, 2003.

LEAL, R. Using accounting information in prospectuses to invest in Brazilian IPOs during high inflation years. Latin American Business Review, v. 5, n. 3, p. $65-90,2004$

MILLER, M. The Modigliani-Miller propositions after thirty years. The Journal of Economic Perspectives, v. 2, n. 4, p. 99-120, 1988.

MITTON, T. Why Have Debt Ratios Increased for Firms in Emerging Markets? Brigham-Young University working paper, 2006. Disponível em http:// ssrn.com/abstract $=897581$. Acesso em 12.07.2008.

MODIGLIANI, F; MILLER, M. The cost of capital, corporation finance, and the theory of investment. American Economic Review, v. 48, n. 3, p. 262-297, 1958.

MODIGLIANI, F; MILLER, M. Corporate income taxes and the cost of capital: a correction. American Economic Review, v. 53, n. 3, p. 433-443, 1963.
PEROBELLI, F; FAMÁ, R. Fatores determinantes da estrutura de capital para empresas latino-americanas. Revista de Administração Contemporânea, v. 7, n. 1, p. 9-35, 2003.

RAJAN, R; ZINGALES, L. What do we know about capital structure? Some evidence from international data. Journal of Finance, v. 50, n. 5 , p. 1421-1460, 1995.

ROCCA, C; SILVA, M; DE CARVALHO, A. Sistema financeiro e a retomada do crescimento econômico. FIPE/Bovespa, 1998

SINGH, A. How do large corporations in developing countries finance their growth? In: O'BRIEN, R. Finance and the International Economy 8 , Oxford: Oxford University Press, p. 121-142, 1994.

STANDARD \& POORS, Global stock markets factbook. New York: Standard \& Poors, 2007.

TERRA, P. An empirical investigation on the determinants of capital structure in Latin America. In: Encontro Nacional da Associação Nacional dos Programas de Pós-Graduação em Administração, 26., 2002, Salvador. Anais... Curitiba: ANPAD, 2002. 